\title{
Citizen Engineering: Disrupting Expertise in Classroom and Community
}

\section{Dr. Donna M. Riley, Virginia Tech}

Donna Riley is Professor of Engineering Education at Virginia Tech.

\section{Jonathan Grunert, Virginia Tech}

Jonathan Grunert is a graduate student in Virginia Tech's department of Science and Technology in Society, with backgrounds in history and library science. His broader interests are in the history of scientific representation. He has taught courses in American history, Science and Society, and Engineering Cultures.

\section{Mr. Yousef Jalali, Virginia Tech}

\section{Dr. Stephanie G. Adams, Old Dominion University}

Dr. Stephanie G. Adams is the Department Head and Professor of Engineering Education at Virginia Tech. She previously served as Associate Dean for Undergraduate Studies in the School of Engineering at Virginia Commonwealth University and was a faculty member and administrator at the University of Nebraska-Lincoln (UNL). Her research interests include: Teamwork, International Collaborations, Faculty Development, Quality Control/Management and Broadening Participation. She is an honor graduate of North Carolina A\&T State University, where she earned her BS in Mechanical Engineering, in 1988. In 1991 she was awarded the Master of Engineering degree in Systems Engineering from the University of Virginia. She received her Ph.D. in Interdisciplinary Engineering from Texas A\&M University in 1998. She is the recipient of numerous awards and honors, including the National Science Foundation's most prestigious, Faculty Early Career Development (CAREER) award. She is a Fellow of the American Society of Engineering Education, holds membership in a number of organizations and presently serves on the National Advisory Board of the National Society of Black Engineers. 


\title{
Citizen Engineering: Disrupting Expertise in Classroom and Community
}

\begin{abstract}
A new engineering course at a large land-grant university seeks to introduce non-engineers to the profession via a combination of artistic endeavors, social science analyses, engineering design thinking, and community practice. The course introduces a new concept, "citizen engineering," borrowed from a tradition of citizen science in which community members ("non-experts") identify scientific questions and proceed through a formal process, such as participatory action research, to seek answers to their questions by defining and driving their own processes of inquiry and analysis, sometimes but not always with the cooperation of trained scientists.

The course first introduces multiple definitions of engineering and citizenship for critical discussion, develops the idea of citizen engineering from citizen science, and then proceeds to a unit on Making where students ponder through examination of examples from art exhibits and popular media what kinds of activities might constitute Making, and which might constitute citizen engineering, and why. The students engage in various Making activities including a short project in which they design and build prototypes of an artifact to improve dorm life. After this, students gain an introduction to engineering studies through analysis of the co-construction of technology and society, and through examining the roles of citizens in large engineering projects such as nuclear power or gas pipelines. Throughout the course there is an underlying argument that non-engineers can and should engage engineering, problematizing the notion of engineering expertise as unique. A series of short essays encourage students to analyze engineering as a profession and consider their own roles as citizen engineers with the power to intervene as nonexperts in engineering activities that impact society.
\end{abstract}

In this first iteration of the course, one of the authors served as a participant-observer and ethnographer focused on student learning. The observer witnessed student engagement with course topics and with one another, and interviewed all the students in the class $(n=5)$ individually. Using the observer's analysis of his observation notes and interview responses, and using the instructors' analysis of student work and course feedback, we reflect on the outcomes of this first iteration of the course and consider avenues for improvement.

Although the course was designed for non-engineers and particularly students outside of STEM fields, those who enrolled for this iteration were three seniors majoring in the sciences, and three first year students who intend to major in engineering but are not yet admitted to the engineering college. This population of students struggled with critical analysis and in particular with the central argument of the course that engineering ought to be democratized, that non-engineers can make crucial contributions that improve engineering practice and hold engineering accountable for its roles in society. Improved reading selection, better scaffolding for more challenging 
readings, alterations to pace and depth for certain concepts such as ethics, and smoothing out logistical challenges with the course should result in improved student learning.

\section{Introduction}

A new engineering course at a large land-grant university seeks to introduce non-engineers to the profession via a combination of artistic endeavors, social science analyses, engineering design thinking, and community practice. The course introduces a new concept, "citizen engineering," borrowed from a tradition of citizen science in which community members ("non-experts") identify scientific questions and proceed through formal processes, such as participatory action research, to systematically seek answers to their questions by defining and driving their own processes of inquiry and analysis, sometimes but not always with the cooperation of trained scientists. ${ }^{1,2}$. Extending this analogy to engineering additionally entails community participation in engineering processes such as problem formulation, establishing design criteria, ideation, evaluation of design alternatives, Making and fabrication, iteration, and more. ${ }^{3}$

In this paper we provide background on course development in our institutional context; motivate the course organizational theme of Citizen Engineering; describe learning outcomes developed from research findings and the course content and activities designed to meet those outcomes; describe findings from independent course observations, student feedback, and evaluation of student work; and reflect on the course, discuss administrative obstacles we encountered, and identify paths for future research and course development.

\section{Context and Background}

The new Citizen Engineering Course builds on two traditions at the institution: the presence of a strong Science and Technology in Society (STS) department in the College of Liberal Arts and Human Sciences, and the university's Curriculum for Liberal Education (CLE), which ensures graduates attain knowledge across six classic content areas in the liberal arts, and is currently under revision in academic year 2015-16. Our STS program has a core strength in Engineering Studies, and has offered a course since 1995, Engineering Cultures, which helps engineers

understand and reflect on their own problem- solving activities as perspectives that both could have been otherwise and must live amidst other perspectives. The principal means is to help students learn about engineering in different times and places sufficiently that they can recognize, understand, respect, and possibly even value perspectives other than their own. For students trained to understand problems as given and answers as either right or wrong, putting in historical and global perspective what they value in themselves is no easy task. ${ }^{4}$

This course has been replicated and enhanced at other institutions around the country and online, ${ }^{5-7}$ and is part of the CLE at our institution. 
Against this backdrop, our institution received a WIDER grant from the National Science Foundation ${ }^{8}$ to conduct research to elicit and characterize essential components of engineering literacy, with the aim of making engineering literacy part of the Curriculum for Liberal Education. Where the Engineering Cultures course offers engineers an opportunity to develop cultural competencies through the CLE, a new course would be designed to offer engineering competency development to non-engineers.

The course was designed based on findings from the first year of the project identifying core competencies for engineering literacy and characterizing how faculty and students value excellence in teaching and active learning within the liberal education curriculum. These were developed from a literature review, a review of CLE course syllabi, teaching evaluation surveys, interviews, and focus groups, building a broad and expansive conceptualization "with engineering knowledge as a key component in discussing and offering critical perspectives about issues that surround social needs." 9 The components used in the course were ultimately adapted from Chae and colleagues' work ${ }^{10}$ and included abilities to do the following:

- discuss, critique, and make decisions about national, local, and personal issues that involve engineering solutions;

- understand and explain how basic societal needs (e.g., water, food, and energy) are processed, produced, and transported;

- solve basic problems faced in everyday life by employing concepts and models of science, technology, and mathematics.

\section{Why Citizen Engineering?}

Unlike its parallel, citizen science, the phrase citizen engineering has not been in common use. A book on engineering ethics entitled Citizen Engineer ${ }^{11}$ emphasizes the duties of professional engineers to act as citizens (i.e. work in the public interest), but it does not consider democratized notions of non-engineer citizens engaging engineering. Ed Layton's history of the formation of engineering as a profession in the US in the Progressive Era ${ }^{12}$ reveals some early conceptualizations of engineers working in the public interest, or at least citing the public interest as a noble aspiration for the profession. However, Layton carefully shows how engineers are primarily concerned with the status of the profession and therefore reserve for themselves alone a sphere of action as privileged experts isolated from the very public that the profession purports to serve.

Engineering historian Matt Wisnioski ${ }^{13}$ documents a 1960s resurgence of engineers working toward the public interest through projects such as Volunteers in Technical Assistance (VITA) and the Committee for Social Responsibility in Engineering (CSRE). While the former employed volunteerism and appropriate technology frameworks and the latter focused on social action in opposition to the military-industrial complex, neither group questioned the role of engineers as technical experts in society. 
These notions stand in contrast to the strong tradition - in certain strands of citizen science - of democratization of science and community collaborations in which expertise is shared. ${ }^{1,14,15}$ It is this contrast of orientations toward expertise that caused us to frame the course around a concept of citizen engineering that parallels the democratized strain of citizen science. The authors' prior experience in science and engineering classrooms and in community-based learning projects related to engineering ${ }^{16-18}$ suggest that disrupting the notion of engineers' expertise is central to both non-engineers gaining confidence to attempt engineering and engineers developing epistemic humility to work across disciplines. ${ }^{19}$

Therefore, the disruption of engineering expertise is a central goal of the course. We use disruption here not as innovation jargon ${ }^{20}$ but rather in the common sense of a disturbance that interrupts one's course. By questioning the commonly held assumption, shared by engineers and non-engineers alike, that engineers hold, or ought to hold, particular expertise and power around technology, we seek for learners to come into their own sense of engineering agency, which in turn facilitates engineering literacy.

In May 2015, while ruminating on the design of this course, one of us (Riley) attended a weeklong workshop at the Highlander Research and Education Center in Tennessee, where she learned of the Highlander ideal of popular education and their strain of participatory action research ${ }^{1}$ implemented in Appalachia. For example, in the 1970s at Bumpass Cove, TN, citizens collected data in their community and conducted research at the Highlander Center to expose illegal dumping of hazardous wastes in their community, which had rendered their rivers unfishable, among other negative environmental impacts. The citizens in the community began with no prior expertise and some without a high school education. Their research forced the state of Tennessee to take action and end the illegal dumping. As the cleanup progressed, the community members became not only citizen scientists, but also citizen engineers as they provided input into design processes for environmental remediation. ${ }^{21}$

While the use of the word citizen is clearly problematic in the term citizen science or citizen engineering because of its connotations of national citizenship, we chose to adopt the term and deliberately problematize it, teaching notions of critical citizenship that delink the word from nationalist and xenophobic notions, reclaiming it for a broader notion of personhood. ${ }^{22-24}$

\section{Course Description}

In order to obtain approval for the course to meet requirements for the Curriculum on Liberal Education, the wording of our learning objectives matched the requirements for the CLE. It was something of a surprise to us that the course was not considered appropriate to meet either the science or social science areas but was instead considered appropriate for art and design because of its focus on the latter. Thus the learning objectives for the course were finalized as follows: 
1. Explore the interaction of engineering design and society, including the contributions of diverse groups with and outside of the profession;

2. Understand how those who produce engineered designs have shaped their ideas via formal engineering design processes and informal processes such as Making;

3. Examine intuitive and metaphorical thought processes in engineering design and their relationship to the human imagination and other intellectual abilities including engineering analysis;

4. Participate in interpretive discussions, lectures, and demonstrations led by engineers, Makers, and other citizens;

5. Explore connections between engineering design and other forms of design and creativity.

In particular, "intuitive and metaphorical thought processes" and "interpretive discussions, lectures, and demonstrations" would not have been a primary emphasis of the course if it had been tied to a different area of the CLE. This spurred creativity on our part and opened up new spaces for exploration as described below.

\section{Content and Activities}

The course consisted of four units:

- What is engineering? What is citizenship? What might citizen engineering be?

- Making

- Engineering, Technology and Society

- Case Studies of Citizen Engineering, including a local project

Developing definitions of Citizen Engineering. Through a series of readings and discussion, students explored multiple definitions of engineering (which they were asked to provide as class preparation). They read and critiqued the NAE Grand Challenges report ${ }^{25}$ and participated in a lesson designed to consider the ethics of the Grand Challenges, ${ }^{26}$ including brainstorming how the Grand Challenges might have been differently defined if non-engineers and non-experts had played a greater role. Introduction to design thinking in engineering and other disciplines followed some of the now classic texts and exercises in first year engineering, ${ }^{27-28}$ and incorporated some less conventional creative explorations based in the dramatic arts. ${ }^{29,30}$ Definitions of critical citizenship were explored through three readings. ${ }^{22-24}$ To initiate conversation of what citizen engineering might be, students read a piece on participation action research as a tool for citizen science ${ }^{1}$ and explored a number of efforts in design, many of them presented in art exhibits and developed by artists rather than engineers, that represent possible examples of citizen engineering. ${ }^{31-38}$ Students spent the rest of the semester collecting examples of citizen engineering and presented these toward the end of the course.

Making. The Maker movement is a confluence of "do-it-yourselfers," Whole Earth Catalogue technologists, and others who see opportunities in the emergence of low-cost fabrication 
techniques. Maker spaces, organized by and for members of the public with any level of technical expertise, offer a multiplicity of visions tied together by the common thread that these are supportive, collaborative places where users can creatively explore technology and build designs toward any purpose they choose.

The central question of the unit on Making was whether and in what ways Making might represent a type of citizen engineering (or not). Can it can be practiced in ways that truly support citizen autonomy and community-based participation? After viewing Dale Dougherty's TED talk motivating making ${ }^{39}$ as homework, a class discussion explored these questions in light of the earlier examples of citizen engineering presented in class. Adapting exercises from a course in Critical Making ${ }^{40}$ for a novice audience, the students engaged several short-term in-class teambased exercises and one larger (but still brief) project in which they design and build prototypes of an artifact to improve dorm life. Again, the exercises drew more upon art than would normally be expected in an engineering course; for example, students were asked to construct from cardboard various expressions of abstract feelings and ideas. ${ }^{40}$ Students developed prototypes for a modular easily collapsible and inexpensive shelving unit; a drop-down desk and collaborative workspace; and a stool/ladder/nightstand combination unit.

Engineering, Technology, and Society. Following on the hands-on Making unit, students considered the co-construction of technology and society through classic STS readings ${ }^{41}$ and scholarship in participatory design. ${ }^{3,42}$ This exploration led directly to a consideration of the roles of citizens in large engineering projects in the energy and transportation sectors, including case studies of local opposition to the proposed Mountain Valley Pipeline, the DC Water lead contamination case (with some current discussion of the crisis that was unfolding in Flint at the time), and the successful efforts of the Clean Air Coalition in Tonawanda, NY to fight air pollution from a local power plant and bridge expansion project. ${ }^{43-50}$ Students attended a public meeting of the group opposing the local fracked gas pipeline project. Throughout the course there is an underlying argument that non-engineers can and should engage engineering, problematizing the notion of engineering expertise as unique. The engagement with the local anti-pipeline group that had significant knowledge about the project readily demonstrated this principle for the students who were completely new to the pipeline, its technical details, and its potential impacts on the region.

A series of short essays encouraged students to analyze engineering as a profession and consider their own roles as citizen engineers with the power to intervene as non-experts in engineering activities that impact society.

\section{Observation and Student Feedback}

In this first iteration of the course, one of the authors served as a participant-observer and ethnographer focused on student learning. The observer witnessed student engagement with course topics and with one another, and interviewed five students in the class individually. Additionally, one author was the grader for the course and his reflection on student work is 
included here as well. A more detailed account of the methods and findings of the interviews and observations as they relate to the development of engineering literacy are presented separately to the Technological Literacy/Engineering and Philosophy Division (TeLPhE) ${ }^{51}$

\section{Interviews and Observations}

Methods. Observations in the class and interviews with five students (83\%) were the primary method of encouraging students to explain their own perceptions of their engineering literacy. ${ }^{52-}$

${ }^{54}$ The semi-structured interviews focused on several aspects that could measure how their literacy changed, namely, in what they anticipated when they enrolled in the course and how the course met their expectations. Participant observation allowed the researcher to gain rapport with the students, while seeing firsthand the ways the students interacted with the concepts presented in the course. Informed consent was obtained per the requirements of our Institutional Review Board (IRB).

The format of the interview was simple. A graduate research assistant arranged to meet with the students in a public, yet quiet, space at the university, where the research assistant asked six questions, with room within the questions for additional, probing questions. The core questions centered around expectations of the course, perceived improvements in engineering literacy, and connecting engineering with majors and with citizenship.

Observations continued over the course of the semester, with all class periods observed. Activities in the course were documented, as were notes on assigned readings. All notes were documented through the researcher's jottings, which were transcribed by the researcher and annotated within a day of the class period. All students are described here by pseudonyms to protect their anonymity.

Findings. A large component of what we found in the course of observations and interviews was an increase in confidence regarding action as citizens with engineering projects. "Confidence" emerged as students' choice of language, unprompted by our interview protocol (see Appendix).

Though students were initially hesitant to participate fully in conversations regarding engineering, especially critiques of engineering mindsets, they became more comfortable offering such critiques, as their confidence in discussing engineering increased. One student, Marley, found "a little more confidence and know more about it [engineering] than I did before." Another, Milburn, noticed that he was able to engage with engineering more deeply:

I guess like my confidence is somewhat altered, because the way I look at things is more in-depth, so I have more confidence in what I say instead of like saying something that has no backing or saying something that I really don't have much knowledge about. Like if I actually look at it from the point of view of like an engineer looking at it, the way we've been looking at it this semester, I have more background knowledge to like back up my argument. 
Their confidence increased in other areas, too. With several practice runs in the Making unit, students became more comfortable working in the engineering lab, knowing who could help and where to find material. Furthermore, they were willing to take more risks, looking at different notions of what would work for their constructions.

Two of the other students corroborated increases in confidence; Reness said, "My confidence in being able to like understand a more comprehensive view of projects has increased. [...] Outside of my academics, engineering is just like a part of life that you have to try to understand in order to work well within the system." Rowena explained:

I think before I felt like, I couldn't interface because I wasn't super familiar with all the engineering things. But going to the [Mountain Valley] pipeline meetings and saying, wait, I don't know what you're talking about, and just having someone explain the vocabulary they're using, I feel like I become more able at realizing what I don't know and how to figure out how to learn that. In order to act with engineers, not necessarily maybe act $a s$ an engineer.

Students exited the course with a broader understanding of the components of engineering, that it is not a discrete part of society, nor is it apolitical. Instead, engineers are full people, complicated and involved in many communities. One student, who intends to major in engineering, said that this course encouraged him to enter the engineering field "with more of a mind toward citizens, non engineers and non experts. More of a willingness to cooperate with them directly on any local projects that directly affect them."

In observing the course, we found that students were most uncomfortable with the topics of ethics and participatory action research. Though through the interviews students revealed some understanding of these topics, their engagement was superficial at best. To be clear, students understood broadly the ethical responsibilities of engineers ("They have a moral obligation to try and help out the general public"), but the responses did not get any more complex. Students also saw participatory action research as something engineers could do, though not necessarily in their roles as engineers, divorcing "citizen" from "engineer" in many responses, as two completely separate entities.

In their course reflections administered by the instructor, it is interesting that students requested more time be spent on both ethics and the participatory action research aspects of the course, and less on Making activities. Often students shy away from those areas that make them uncomfortable and it speaks well of these particular students that they requested more time spent on the areas that challenged them most.

Students expressed their primary achievement in the course as learning how to better read engineering literature. The confidence gained through the course made the students more comfortable in their abilities to converse, to comprehend, and to understand a variety of 
engineering topics. This finding is particularly encouraging as it is an indication of improvement in students' engineering literacy, and in their becoming better citizens.

\section{Student Work}

Methods. Students were evaluated based on several essay assignments related to course readings and concepts applied in everyday life; their Making exercises, projects, and presentations; logbook entries, including sketches, reflections, ideas, and notes; participation in a local citizen engineering project of their choosing; engagement in classroom discussions; and an end-of-semester portfolio and reflection on learning. With only six students in the course, our analysis here takes the form of informal reflection from the perspective of one author who served as the graduate teaching assistant and grader for the course.

Findings. The hands-on assignments with Making provided students an opportunity to not only get involved in an engineering design process, but also appreciate the role of non-engineers, like themselves, in addressing everyday problems related to engineering. In the Making projects, pairs of students creatively identified and addressed problems in their dormitory environment following the design process: defining needs and design requirements, brainstorming and developing ideas, evaluating them, iterating on these steps, building a prototype, and suggesting possible ways of validating their design. Students demonstrated strong abilities to identify possible practical interaction of engineering design and society and artistically build prototypes which can help them to improve their environment. As stated by students in their report, time constraints and lack of access to a greater variety of materials were two obstacles preventing them from further developing their projects.

Students also were very engaged in their writing assignments, in which they demonstrated their understanding of the concept of citizen engineering, and explored the interconnectedness of technology and society. Students were evaluated based on writing quality, argumentation, engagement with course materials, and making connections with everyday life. Each assignment included a rubric that explicitly spelled out specific evaluation criteria. For example, all essays included criteria on writing quality and argumentation, as well as topic-specific criteria (e.g., on ethics, or critical analysis of technology in society):

WRITING QUALITY - Writing is clear, concise, and logical, with sufficient detail, free from casual language, grammatical errors and awkward sentence construction. Words are used correctly. Superfluous information omitted. Essay is well-structured with a clear introduction, development of thesis with supporting statements, and recapitulation that summarizes the main arguments. Document is professional in appearance, follows specified length guidelines, etc. 


\begin{abstract}
ARGUMENTATION - Sources are cited in APA format, including course readings and ethical frameworks used. Sources appropriately and sufficiently support argument. Support is specific and precise. Critical thinking is evident in consideration of multiple ethical frameworks and stakeholder perspectives.

Counterarguments are anticipated and addressed. Statements are consistent within the context of the essay, without logical flaws. Avoids universalizing and oversimplification. Argument progresses logically and sequentially. Argument is persuasive and compelling.
\end{abstract}

Some students struggled with the writing assignments initially. However they showed improvement throughout the semester as measured through rubric scoring, responding to constructive comments provided using the assignment rubrics as a guide. In addition to rubric criteria, students learned through feedback to improve the flow of their writing through better transitions between ideas, and improved argumentation by following a claim-reason-evidence argumentation model. The quality of reflection improved over the course of the semester, as students engaged with course materials. Some exceeded expectations by critically engaging the concept of citizen engineering, successfully developing creative applied examples, and critiquing mainstream engineering practices based on course readings.

\title{
Discussion
}

The findings document some disruption of engineering expertise, with students gaining some agency and confidence in their discussions of engineering. At the same time, we did not find that students fully embraced a role of citizen engineer. Ultimately it may require a more direct confrontation of engineering expertise, either through a more immersive community based learning experience, and/or by reading and explicitly discussing the science and technology studies literature on this topic, to scaffold students' development in this area.

Our experience overall with the course needs to be understood within our institutional context, described in the introduction and course description. Although the course was designed for nonengineers and particularly students outside of STEM fields, those who enrolled for this iteration were three seniors majoring in the sciences, and three first-year students who intend to major in engineering but are not yet admitted to the College of Engineering. There was a mismatch between the course as designed for non-STEM students, and an enrollment of 100\% STEM students that will be corrected in the future, probably by both recruiting students from social science and humanities majors, and by shifting content and activities to speak to STEM students who are likely to continue to enroll.

One of the major barriers to achieving the desired enrollment population is the fact that the CLE area this course meets is Art and Design. It is not the usual situation where a science literacy course meets a lab science requirement, or a math literacy course meets a quantitative reasoning 
requirement. The way the institution developed and defined its six areas of knowledge for the CLE, and the way power is negotiated across disciplines on the campus, the CLE approval team rejected our bid to designate the course as science (it would have needed a hypothesis-driven lab) and as social science (it would have needed quantitative study of human populations). Thus we ended up with a designation as an Art and Design course (emphasis on design). It is additionally problematic that the College of Engineering charges differential tuition, so that a student majoring in humanities or social sciences must pay additional fees per credit for the course. Students in other majors, such as business, already pay a differential tuition to the business school and are used to seeing these charges.

It was noted early on by the research team that our learning outcomes as driven by the CLE were not easily assessable. While our assessment for this first year with six students was conducted in an open-ended, qualitative fashion rather than a formal quantitative assessment of outcome achievement, we recognize the need to maintain a second set of course objectives for the purposes of assessing student learning and thus rewrote the course objectives for future use as shown in Table 1.

Several issues account for the low enrollment. First, on this tech-intensive campus, excluding engineers from registering for the course significantly shrinks the pool of possible enrollees. Second, there was a delay in getting the course approved as part of the Curriculum for Liberal Education because of the ongoing revision process on campus. Due to this delay, the course was not available during spring registration for fall courses, nor during first-year registration in July. The only time the course was available for registration was during add/drop in the first two weeks of classes. Because of the transition and the status of the course as a pilot, students searching for courses to meet the CLE requirements don't see this course. They must rely on information from peers or advisors to become aware of the course as a means to meet their CLE requirement. We spread word through a flyer distributed through networks of associate deans and advisors across colleges, but it simply did not yield many students.

This population of students struggled with critical analysis and in particular with the central argument of the course that engineering ought to be democratized, that non-engineers can make crucial contributions that improve engineering practice and hold engineering accountable for its roles in society. Improved reading selection, better scaffolding for more challenging readings, alterations to pace and depth for certain concepts such as ethics, and smoothing out logistical challenges with the course should result in improved student learning.

As the university moves forward the rollout of the new curriculum for liberal education, the fit with the new categories should be better, as it will squarely fit in a new design area. The new curriculum supports creative interdisciplinary minors, and this course is currently a potential candidate for two such minors, and may become part of the undergraduate curriculum in Science, Technology, and Society as that develops. All of these collaborations will increase course 
interest and enrolment, and represent excellent opportunities for non-engineers to interface with engineering through the liberal arts.

\begin{tabular}{|c|c|c|}
\hline \multicolumn{3}{|c|}{ Table 1: Course Outcomes and Interview Frames for Citizen Engineering } \\
\hline Original & Revised & Interview Frame \\
\hline $\begin{array}{l}\text { Explore the interaction of } \\
\text { engineering design and } \\
\text { society, including the } \\
\text { contributions of diverse } \\
\text { groups with and outside of the } \\
\text { profession; }\end{array}$ & $\begin{array}{l}\text { Students will be able to } \\
\text { explain the interaction } \\
\text { between engineering design } \\
\text { and society. } \\
\text { Students will be able to } \\
\text { explain the contributions of } \\
\text { diverse groups to the } \\
\text { interaction between } \\
\text { engineering design and } \\
\text { society. }\end{array}$ & $\begin{array}{l}\text { Can you talk about } \\
\text { engineering design and } \\
\text { society? } \\
\text { Are there any particular } \\
\text { groups of individuals who } \\
\text { have contributed to } \\
\text { engineering design and } \\
\text { society? How? }\end{array}$ \\
\hline $\begin{array}{l}\text { Understand how those who } \\
\text { produce engineered designs } \\
\text { have shaped their ideas via } \\
\text { formal engineering design } \\
\text { processes and informal } \\
\text { processes such as making; }\end{array}$ & $\begin{array}{l}\text { Students will be able to } \\
\text { demonstrate how formal and } \\
\text { informal design processes } \\
\text { contribute to engineering } \\
\text { design. }\end{array}$ & $\begin{array}{l}\text { Can you talk about formal } \\
\text { and informal design } \\
\text { processes? } \\
\text { Do these relate to } \\
\text { engineering design? How? }\end{array}$ \\
\hline $\begin{array}{l}\text { Examine intuitive and } \\
\text { metaphorical thought } \\
\text { processes in engineering } \\
\text { design and their relationship } \\
\text { to the human imagination and } \\
\text { other intellectual abilities } \\
\text { including engineering } \\
\text { analysis; }\end{array}$ & $\begin{array}{l}\text { Students will be able to } \\
\text { demonstrate the impact of } \\
\text { intellectual abilities (e.g., } \\
\text { intuition, imagination) on } \\
\text { engineering design. }\end{array}$ & $\begin{array}{l}\text { We hear a lot today about } \\
\text { imagination, creativity, and } \\
\text { intuition. Are these related to } \\
\text { design thinking? How? }\end{array}$ \\
\hline $\begin{array}{l}\text { Participate in interpretive } \\
\text { discussions, lectures, and } \\
\text { demonstrations led by } \\
\text { engineers, makers, and other } \\
\text { citizens; }\end{array}$ & $\begin{array}{l}\text { Students will be able to } \\
\text { describe key lessons learned } \\
\text { through their participation. }\end{array}$ & $\begin{array}{l}\text { Describe one of the events } \\
\text { you attended on campus or in } \\
\text { the community. What did } \\
\text { you learn? }\end{array}$ \\
\hline $\begin{array}{l}\text { Explore connections between } \\
\text { engineering design and other } \\
\text { forms of design and creativity. }\end{array}$ & $\begin{array}{l}\text { Students will be able to } \\
\text { illustrate connection between } \\
\text { engineering design and non- } \\
\text { engineering design. }\end{array}$ & $\begin{array}{l}\text { Is there a relationship } \\
\text { between engineering design } \\
\text { and non-engineering design? } \\
\text { What might this look like? }\end{array}$ \\
\hline
\end{tabular}




\section{Conclusions}

The concept of citizen engineering has proven to be a useful organizing tool for an engineering literacy course designed to introduce non-engineers to the field in a way that has resonance and relevance for students across disciplines, emphasizing interactions between technology and society, and public participation in engineering projects. After the first offering the course we have identified challenges within the institutional structure that we hope will improve with the rollout of a new curriculum for liberal education, and challenges students faced with some of the assignments and material that we will address with new readings, shifting emphases on different aspects of the course based on student feedback, and better scaffolding of student learning in some areas.

\section{Acknowledgements}

This material is based upon work supported by the National Science Foundation (NSF) under grant number 1256529. Any opinions, findings, and conclusions or recommendations expressed in this material are those of the authors and do not necessarily reflect the views of the NSF.

\section{References}

1. Merrifield, J. (n.d.; c. 1985). Putting Scientists in their Place: Participatory Research in Environmental and Occupational Health. New Market, TN: Highlander Research and Education Center.

2. von Hippel, F. (1990). Citizen Scientist. New York: American Institute of Physics.

3. Nieusma, D. (2004). Alternative Design Scholarship: Working Towards Appropriate Design. Design Issues, 20(3): 13-24.

4. Lucena, J., \& Downey, G. L. (1999, June), Engineering Cultures: Engineering Problem Solving Through Humanistic And Global Perspectives. Paper presented at 1999 Annual Conference, Charlotte, North Carolina. https://peer.asee.org/7632.

5. Parkhurst, R., \& Moskal, B., \& Lucena, J., \& Bigley, T., \& Downey, G., \& Ruff, S. (2006, June), A Comparative Analysis Of Online And In Class Versions Of Engineering Cultures Paper presented at 2006 Annual Conference \& Exposition, Chicago, Illinois. https://peer.asee.org/672.

6. Jesiek, B. K., \& Chang, Y., \& Shen, Y., \& Lin, J. J., \& Hirleman, D., \& Groll, E. A. (2011, June), International Research and Education in Engineering (IREE) 2010 China: Developing Globally Competent Engineering Researchers Paper presented at 2011 Annual Conference \& Exposition, Vancouver, BC. https://peer.asee.org/18149.

7. Bland, L. (2010, June), Impact Of Cross Cultural Study Experiences On Cultural Sensitivity Development Paper presented at 2010 Annual Conference \& Exposition, Louisville, Kentucky. https://peer.asee.org/16409.

8. Adams, S.G., Doolittle, P., Wubah, D., Van Dyke, R., and Campbell, W. (2012). WIDER: EAGER: A SelfAssessment of Evidence-based Instructional Practices and Outcomes in STEM-related Core Courses for STEM Majors and Non-Majors. National Science Foundation Award. http://www.nsf.gov/awardsearch/showAward?AWD_ID=1256529

9. Grunert, J., Doolittle, P., and Adams, S. G. (2015). Reaching Out to the Masses: Building Literacy about Engineering Amongst Non-engineering Students. ASEE Annual Conference Proceedings, June 14-17, Seattle, WA. 
10. Chae, Y., Purzer, S., and Cardella, M. (2010). Core concepts for engineering literacy: The interrelationships among STEM disciplines. ASEE Annual Conference and Exposition, Conference Proceedings, 2010.

11. Douglas, D. and Papadopoulos, G. (2009). Citizen Engineer: A Handbook for Socially Responsible Engineering. Crawfordsville, IN: R.R. Donnelly.

12. Layton, E. T. (1971). The Revolt of the Engineers: Social Responsibility and the American Engineering Profession. Cleveland: Case Western Reserve Press.

13. Wisinioski, M.H. (2012). Engineers for Change: Competing Visions of Technology in 1960s America. Cambridge, MA: MIT Press.

14. Hollander, R. (1984). Institutionalizing Public Service Science: Its Perils and Promise. In Citizen Participation in Science Policy, J.C. Peterson, ed. Amherst: University of Massachusetts Press, pp. 75-95.

15. Sclove, R.S. (1995). Democracy and Technology. New York: Guilford Press.

16. Riley, D.M. and Bloomgarden, A. (2006). Learning and Service in Engineering and Global Development. International Journal of Service Learning in Engineering, 1 (2): 48-59.

17. Riley, D. and Armstrong, E. (2005). Common Ground: How a course collaboration between engineering and women's studies produced fine art. ASEE Annual Conference Proceedings, June 12-15, Portland, OR.

18. Nieusma, D. and Riley, D. (2010). Designs on Development: Engineering, Globalization, and Social Justice. Engineering Studies 2(1): 29-59.

19. Riley, D. and Lambrinidou, Y. (2015). Canons against Canons? Social Justice and the Engineering Ethics Imaginary. ASEE Annual Conference, 2015.

20. Christensen, C. (1995). Disruptive Technologies: Catching the Wave. Harvard Business Review, 73(1): 43-53.

21. Couto, R.A. with Guthrie, C.S. (2010). Making Democracy Work Better: Mediating Structures, Social Capital, and the Democratic Prospect. Chapel Hill, NC: University of North Carolina Press.

22. WynSculley, C. (2012). A working definition of critical citizenship. Critical Citizenship [blog]. https://criticalcitizenship.wordpress.com/2012/01/17/hello-world/

23. Giroux, H. (1993). Schooling for Critical Citizenship. Synthesis/Regeneration 5 (Winter 1993). http://www.greens.org/s-r/05/05-10.html.

24. Elam, M. and Bertilsson, M. (2003). Consuming, Engaging, and Confronting Science, European Journal of Social Theory, 6(2): 233-251.

25. National Academy of Engineering (2008). Grand Challenges of Engineering. http://www.engineeringchallenges.org/File.aspx?id=11574\&v=ba24e2ed

26. Riley, D. (2012). We've Been Framed! Ends, Means and the Ethics of the Grand(iose) Challenges. International Journal of Engineering, Social Justice, and Peace, 1(2): 123-136.

27. Dym, C. and Little, P. (2008). Engineering Design: A Project Based Introduction. New York: Wiley.

28. Nightline, ABC (1999). The Deep Dive. Aired July, 13, 1999.

29. Alger, D. (2015). Rules of Improv Part I. Oakland, CA: Pan Theater. http://www.pantheater.com/articles-rulesof-improv-part-i-improv-comedy.html

30. Boal, A. (1992). Games for Actors and Non-Actors. Translated by Adran Jackson. New York: Routledge.

31. Rosner, D. and Bean, J. The Weapons Factory in the Den. Interactions 20(3): 80-81. http://people.ischool.berkeley.edu/ daniela/files/p80-rosner.pdf

32. cárdenas, m., Cullors, P., Betts, E., and Head, C. (2015). UNSTOPPABLE. http://www.werunstoppable.com/

33. Temporary Services and Angelo. Prisoners' Inventions. Chicago: White Walls, 2003. http://temporaryservices.org/served/projects-by-name/prisoners-inventions/

34. Museum of Modern Art. SAFE: Design Takes on Risk. New York, MoMA, 2006. http://www.moma.org/interactives/exhibitions/2005/safe/

35. Smith, C. Design for the Other 90 Percent. New York: Cooper Hewitt Museum. http://archive.cooperhewitt.org/other90/other90.cooperhewitt.org/index.html

36. Safecast (2015). http://www.safecast.org.

37. Radcast (2015). http://www.radcast.org.

38. McQuillan, D. (2013)., https://storify.com/danmcquillan/what-is-critical-citizen-science-a-dialogue and https://storify.com/danmcquillan/what-is-critical-citizen-science-a-dialogue-part-2. 
39. Dougherty, D. (2011). We are Makers. TED talk. https://www.ted.com/talks/dale_dougherty_we_are_makers?language=en

40. Paulos, E. (2015). Critical Making: Materials, Protocols, and Culture. http://make.berkeley.edu/schedule/

41. Winner, L. (1986). Do Artifacts Have Politics? The Whale and the Reactor. Chicago: University of Chicago Press, 1986. pp. 19-39. http://zaphod.mindlab.umd.edu/docSeminar/pdfs/Winner.pdf

42. Werner, D. (1998) Nothing About Us Without Us: Developing Innovative Technologies for, by, and with Disabled Persons. Palo Alto: HealthWrights.

43. Clean Air Coalition of Western New York (2015). Tonawanda Overview. https://www.cacwny.org/campaigns/tonawanda/

44. Clean Air Coalition of Western New York (2015). Community Control over Public Dollars. https://www.cacwny.org/2015/03/community-control-over-public-dollar/

45. Ramey, C. (2015) America's Unfair Rules of the Road. Slate, February 27, 2015. http://www.slate.com/articles/news_and_politics/politics/2015/02/america_s_transportation_system_discriminat es against minorities and poor.html

46. Shogren, E. (Narrator) (2011, November 10). New York Plant's Neighbors Expose Regulatory Gaps. [Radio broadcast episode]. In S. Bartlett (Producer), All Things Considered. Washington, DC: National Public Radio. http://www.npr.org/2011/11/10/142189390/tonawanda-provides-lessons-for-fighting-toxic-air

47. Barrick, M. (2015). Environmental Scientists, Activist Applaud Mountain Valley Pipeline Ruling. Appalachian Chronicle, August 7, 2015. http://appalachianchronicle.com/2015/08/07/environmental-scientists-activistapplaud-mountain-valley-pipeline-ruling/

48. Leonnig, C.D. (2004). EPA Concludes WASA Broke Lead Law. Washington Post, June 18, 2004, p. B01. http://www.washingtonpost.com/wp-dyn/articles/A50736-2004Jun17.html

49. Leonnig, C.D. (2009). High Lead Levels Found in DC Kids. Washington Post, January 27, 2009.

50. Leonnig, C.D. (2013). Increase in Miscarriages Coincided with High Level of Lead in DC Water, Study Finds. Washington Post, December 9, 2013.

51. Grunert, J., and Adams, S.G. (2016). Increasing Engineering Literacy among Non-engineering Students. ASEE Annual Conference Proceedings, June 26-29, New Orleans, LA.

52. Arksey, H., and Knight, P. (1999). Interviewing for Social Scientists: An Introductory Resource with Examples. London: SAGE.

53. Barriball, K. L., and White, A. (1994). Collecting Data using a Semi-Structured Interview: A Discussion Paper. Journal of Advanced Nursing. 19: 328-335.

54. Burnard, P. (1991). A Method of Analysing Interview Transcripts in Qualitative Research. Nurse Education Today. 11(6): 461-466. 


\section{Appendix: Semi-structured Interview Protocol}

Tell me why you enrolled in this course. What did you anticipate learning? probe: Ask the interviewee to expand beyond classroom learning.

How did you envision it connecting with your major, and with your general education? probe: Ask how the field might benefit from engineering knowledge.

How have you found this course meeting those expectations?

(Interviewee will need additional affirmation that responses will not impact grade) probe: How could the course have improved to meet those expectations?

Describe your experiences with engineering before this course.

probe: Remind interviewee that talking with engineering majors about their major is an experience with engineering.

How has your engineering literacy changed through this semester, especially regarding engineering knowledge, attitude, and abilities?

probe: Negative change is okay

How do you see engineering as a component of your life outside of academic circles? prompt: How to you plan to use what you've learned in this class later? What area(s) of life does/might it appear? 